Review

\title{
Infections with biological therapy: strategies for risk minimization in tropical and developing countries
}

\author{
Carlos E Pérez-Díaz ${ }^{1,2,3}$, Erika Uribe-Pardo¹, Omar-Javier Calixto ${ }^{1}$, Álvaro A Faccini-Martínez4, Alfonso J \\ Rodriguez-Morales ${ }^{5,6}$ \\ ${ }^{1}$ Servicios y Asesorías en Infectología (SAI), Bogotá, Colombia \\ 2 Infectious Diseases Department, Clínica Marly, Bogotá, Colombia \\ 3 Infectious Diseases Department, Hospital de la Samaritana, Bogotá, Colombia \\ ${ }^{4}$ Programa de Pós-Graduação em Doenças Infecciosas, Centro de Ciências da Saúde, Universidade Federal do \\ Espírito Santo, Vitória, ES, Brazil \\ ${ }^{5}$ Public Health and Infection Research Group, Faculty of Health Sciences, Universidad Tecnológica de Pereira, \\ Pereira, Risaralda, Colombia \\ ${ }^{6}$ Organización Latinoamericana para el Fomento de la Investigación en Salud (OLFIS), Bucaramanga, Santander, \\ Colombia
}

\begin{abstract}
In recent decades, biological therapy has enabled disease activity control and improved quality of life in patients with autoimmune diseases. These therapies that are involved in immune response modifications and change multiple immunological pathways induce an incremental risk for certain infectious diseases. Though there have been recent advances in risk assessment for biological therapy, there is a lack of data and recommendations for assessing risks in populations with high prevalence of infectious diseases, such as those located in tropical areas and developing countries. We performed a review on infections with biological therapy as well strategies for risk minimization in areas with a high prevalence of tropical diseases.
\end{abstract}

Key words: autoimmune disease; rheumatoid arthritis; tuberculosis; biological therapy; infectious diseases.

J Infect Dev Ctries 2016; 10(12):1278-1285. doi:10.3855/jidc.8222

(Received 06 February 2016 - Accepted 29 July 2016)

Copyright (C) 2016 Pérez-Díaz et al. This is an open-access article distributed under the Creative Commons Attribution License, which permits unrestricted use, distribution, and reproduction in any medium, provided the original work is properly cited.

\section{Introduction}

Autoimmune diseases (AD) are chronic diseases with common pathophysiology. The most remarkable characteristic is loss of immunological tolerance to selfantigens, which induce immune-related damage affecting tissues, organs, or even body systems simultaneously. The chronic nature of these diseases places a significant burden on health system programs, with a negative impact on disability and quality of life. The prevalence of AD varies among different geographies $[1,2]$. Worldwide prevalence for each $\mathrm{AD}$ is estimated to be $3 \%-8 \%$ for autoimmune thyroid disease, $1 \%$ for rheumatoid arthritis (RA), $0.75 \%$ for psoriasis, and $0.024 \%$ for systemic lupus erythematosus (SLE) [3].

Immunosuppressive agents are the cornerstones of treatment. They induce immune response regulation against auto-antigens, preventing subsequent organ damage and enabling disease control. The main immunosuppressive agents are the corticosteroids and the drug modifying against rheumatic diseases (DMARDs), such as methotrexate (MTX), azathioprine, and sulfasalazine, among others. However, these drugs (mainly corticosteroids) are associated with many adverse events and lack of efficacy in the long term [4].

Over the last decades, the development of biological therapies has led to an advance in the treatment of rheumatic diseases such as RA, psoriatic arthritis, spondyloarthropathy (SpA), and inflammatory bowel disease (IBD), among others. Numerous agents with different immune mechanisms are available, including anti-tumor necrosis factor (anti-TNF) (e.g., adalimumab, etanercept, infliximab, golimumab, and certolizumab pegol), anti-interleukin 1 (e.g., anakinra), anti-interleukin 6 (e.g., tocilizumab), anti-CD28 (e.g., abatacept), anti-CD20 (e.g., rituximab), and antiinterleukin 12/23 (e.g., ustekinumab) [5]. 
The use of biological therapy in patients with $\mathrm{AD}$ has increased in recent years, not just in high-income countries, but also in middle- and low-income countries. According to the Latin American Group for the Study of Rheumatoid Arthritis (GLADAR) registry, approximately $1.1 \%$ of RA patients from Latin America with short duration of the disease are treated with biological therapy [6]. In Europe, in countries such as France, this percentage is higher, with $12 \%$ usage within the first year after diagnosis [7]. In Turkey, patients with RA or SpA reported an average use of anti-TNF agents of $8.9 \%$ [8]. Moreover, patients' access to biologics in Europe (defined as the ratio between biologic annualized treatments and the prevalence of RA) was reported to be as high as 35\% in Ireland and Netherlands and as low as 7\% in Portugal [9]. In Colombia, Montoya et al. described an RA patient cohort with an average use of biological therapy of $36.5 \%$ for a single agent and $8.3 \%$ for two or more agents [10].

There is a greater frequency of arthritis and enthesitis among SpA patients from Latin America (LA) compared with patients from Europe, and approximately $14 \%$ of LA patients were on a biological therapy regimen [11]. In Canada and Italy, the reported use anti-TNF in a cohort of patients with axial spondyloarthritis was $60 \%[12,13]$.

In addition, the use of biological therapy in IBD, comprising ulcerative colitis (UC) and Crohn's disease (CD), should be considered. Infliximab, adalimumab, certolizumab pegol, and golimumab are approved for the treatment of moderate to severe IBD in adults.

In 2009, Andersen et al. performed a single-cohort study evaluating the long-term safety of infliximab in 734 exposed patients with IBD for a median of 58 months, and the results showed that infection rates were similar in patients treated with infliximab compared to patients treated with conventional therapies [14]. Another study from North America combined four large databases in the SABER (safety assessment of biologic therapy) and analyzed the rate of serious infections in patients with AD (including IBD, RA, psoriasis, SpA, and AS) exposed to anti-TNF. Among 2,323 patients with anti-TNF treatment, there was no increased risk for serious infections [15].

The use of biological therapy has been associated with an increased risk for different infectious diseases, including tuberculosis (TB) $[4,15,16]$. Risk minimization strategies (i.e., systematic reduction in the extent of exposure to a risk and/or the likelihood of its occurrence) must be implemented in order to identify those patients at risk of acquiring and/or having a reactivation of an infectious disease during the course of treatment with biological therapy [15]. There are several screening programs around the world for patients receiving biological therapy. However, the incidence of infectious diseases varies among different latitudes, highlighting the importance of having local programs based on the country's epidemiology. The main purpose of this article is to propose a screening program as a risk minimization strategy, specifically designed for patients with AD treated with biological therapy, from tropical and developing countries.

\section{Biological therapy and infection risk}

In the last decade, there have been several publications assessing the risk of infections in patients receiving biological therapy. Its use increases the risk of hospitalizations due infectious diseases even 1.5- to 2 -fold [17]. Recent studies gathered in a meta-analysis found that standard-dose biological drug usage, with or without DMARDs, was associated with increased risk of serious infections [18-22].

An example of variability among different biological drugs was published by the British Society based on its Rheumatology Biologics Register (BSRBR), which reported incidences in users of antiTNF; infliximab and adalimumab presented a higher incidence of TB, 187.5/100,000 and 215/100,000 respectively, compared with $9.3 / 100,000$ presented in the etanercept group [19,21].

Abatacept and rituximab were not associated with significantly higher risk compared to other biological drugs [22]. Possible differences can be attributed to study protocol, and more comparative studies are required.

Moreover, a detailed analysis found that infliximab, certolizumab pegol, and anakinra were associated with high rates of adverse events (AEs) and withdrawals due to AE compared with placebo [19].

\section{Screening program for tropical and developing countries}

Commonly, standard screening programs include laboratory tests such as the tuberculin skin test (TST), interferon gamma release assay (IGRA), chest radiograph, hepatitis $B$ core antibody (anti-HBc), hepatitis B surface antigen (HBsAg), hepatitis B surface antibody (anti-HB) [23,24], hepatitis C antibody, venereal disease research laboratory test (VDRL), IgG for varicella zoster, cytomegalovirus, Epstein-Barr virus, toxoplasmosis, and human immunodeficiency virus (HIV). Additionally, we suggest that the following tests be performed in patients currently living 
or migrating from tropical and developing countries: IgG hepatitis A virus (HAV), IgG Trypanosoma cruzi (Chagas disease), stool test for intestinal parasites, and IgG human T-lymphotropic virus 1-2 (HTLV 1-2).

\section{Hepatitis A virus infection}

HAV was a cause of severe hepatic disease in adults. Before the introduction of the vaccine, the incidence of the disease among travelers was 320/1,000 travelers per month [25]. However, there are no data indicating that HAV is more frequent in immunocompromised patients, although it has been shown that in HIV patients, viremia, liver function tests, and secretion of HAV virus in stool can be prolonged [25]. Some studies recommend the HAV vaccine for patients with rheumatic diseases traveling to countries with high or moderate prevalence [26].

In Sweden, Askling et al. performed a prospective study on HAV vaccination in adult patients with RA who were receiving immunosuppressive therapy. In this study, among 53 patients, 15 treated with anti-TNF, 21 with anti-TNF + MTX, and 17 with MTX, one and six months after the first dose, $10 \%$ and $33 \%$ of the patients, respectively, had attained seroprotection levels; one and six months after the second dose, $83 \%$ and $72 \%$ of patients were seroprotected, and at month $24,86 \%$ of the vaccines showed protective levels. Two doses of HAV vaccines at six-month intervals therefore provided protection for most immunocompromised patients [27].

Colombia and other tropical countries have a high prevalence of HAV. HAV is the most frequent etiologic agent of viral hepatitis [28]. Screening for HAV virus is recommended prior to commencement of biological therapy; if the test is negative, the vaccine must be administered. Ideally, the vaccine should be administered prior to commencement of biological therapy. In fact, in recent years, the use and availability of the HAV vaccine have increased significantly in many developing countries. Given the high incidence of HAV in tropical countries, use of the HAV vaccine would help to reduce its impact in patients receiving biological therapies.

\section{Chagas disease}

Chagas disease should be considered in tropical countries. T. cruzi has usually not been considered to be an opportunistic agent [29]; however, in recent decades, there has been increased reactivation in immunosuppressed patients, mainly in patients with HIV infection and those receiving immunosuppressant treatment such as corticosteroid therapy, and those undergoing transplantation. Some authors described the effectiveness of benznidazole in reducing reactivation rates in patients with $T$. cruzi infection treated with corticosteroid therapy [30-32].

The association between Chagas disease and autoimmune diseases is small, but this may be due to underdiagnosed cases in developing countries [33]. Nevertheless, the chronic phase of Chagas disease is considered to be the result of autoimmune disorders. Some studies reported Chagas reactivation in patients using higher doses of corticosteroids; dos Santos-Neto et al. reported Chagas disease in one patient with SLE treated with cyclophosphamide and corticosteroids with evidence of parasitemia who was successfully treated with beznidazole. However, there is no clear evidence to support treating immunosuppressed patients with prophylactic therapy due to a lack of clinical trials $[34,35]$. However, the relationship between Chagas reactivation and use of immunosuppressive therapy is controversial $[30,36]$.

On the other hand, evidence of biological therapy and Chagas disease reactivation has not been reported. Nonetheless, Pereira et al. assessed the use of anti-TNF drugs in mice infected with $T$. cruzi, showing that TNF is a crucial cytokine in Chagas heart disease; it could generate immunological unbalance, which contributes to cardiac abnormalities [37]. Therefore, the role of TNF in Chagas disease requires further study, especially in immunosuppressed patients.

We recommend that $\mathrm{IgG}$ be assessed for Chagas disease status in countries with high prevalence of the parasite in order to be able to rule out the disease or prevent reactivation. The scope of this recommendation should be extended to other immunosuppressive therapy such as corticosteroids, DMARDs, and cyclophosphamide. This should be particularly considered not only in those countries endemic for Chagas diseases (most in Latin America, from Mexico to Argentina), but also in migrants from these countries to North America and Europe, among other regions.

\section{Intestinal parasitic infections}

Intestinal parasitic infections should also be assessed due to the possibility of reactivation in patients undergoing immunosuppressive therapy. The prevalence of these parasites is very high in our environment [38].

Although in most patients, Entamoeba histolytica presents with an asymptomatic course, in immunocompromised patients, there is a high risk of fulminant amoebic colitis [39]. Amoebiasis prophylaxis should be given before the onset of therapy with 
secnidazole 2 grams orally single dose, and repeated every year if the patient's immunosuppression persists or if the patient lives in an endemic area [38]. Regarding strongylodiasis, some studies have shown an association between SLE patients with corticosteroids and hyperinfection due to Strongyloides stercoralis $[38,40,41]$. This nematode can even migrate in this clinical context to the central nervous system, which is a life-threating condition. Also, since biological therapy has become very important in treating rheumatic disease, it has been suggested that the recommendation of prophylaxis should be extended to this type of therapy $[38,42]$. Prophylaxis should be performed with ivermectin $200 \mu \mathrm{g} / \mathrm{kg} /$ day orally, for two consecutive days, repeated within two weeks, and repeated every six months if immunosuppression persists or the patient lives in an endemic area $[38,43]$.

\section{HTLV infections}

Several cross-sectional studies have found a high prevalence of HTLV-1 among tuberculosis patients and a high prevalence of tuberculosis in HTLV-1 infected patients. HTLV-1 reduces the response to Mycobacterium tuberculosis infection, suggesting that it could increase the risk of disease development [44]. A Brazilian control-case study showed that HTLV-1 patients suffered TB three times more frequently [45]. Patients infected with HTLV-1 have had a higher risk of contracting strongyloidiasis; therefore, we recommend performing this test. HTLV-1 is prevalent in some tropical countries (e.g., Brazil, Peru, Venezuela). Unfortunately, the epidemiology of HTLV infections is largely misunderstood and unknown. In addition to Brazil, Peru has reported significant number of publications showing the seroprevalence and clinical consequences of such infections and interactions with other infectious agents, such $S$. stercoralis $[44,45]$.

\section{Tuberculosis in tropical and developing countries}

According to the literature, starting biological therapy increased the risk of TB reactivation. Moreover, to reduce the risk of TB reactivation, several recommendations have been proposed. These should be adjusted and implemented based on social and economic conditions as well as the prevalence of TB in each particular country $[4,46]$. In countries such as Colombia, TB is a public health issue; there are approximately 11,000 cases per year, with 25.6 cases per 100,000 habitants [47]. Nevertheless, this condition is highly prevalent in other countries of the region such as Peru, Bolivia, and Brazil, among others.
Latent tuberculosis infection (LTBI) screening procedures are mandatory before the commencement of biological therapy. They should include full clinical history, information about country of birth, recent exposure to $\mathrm{TB}$, previous active $\mathrm{TB}$, and treatment completion, along with any additional risks such as drug abuse or alcohol, and adequate physical examination [4]. LTBI is particularly important in some population groups (e.g., Amerindians, prisoners).

Cantini et al. had some recommendations in BCGvaccinated and unvaccinated subjects. The panel recommended using the IGRA over TST in vaccinated subjects due to high false-positive test rates in TST [4]. However, some studies performed in high-burden TB areas showed that BCG vaccination did not interfere with TST results, and considered the test a useful tool after three years of BCG vaccination [48]. In addition, the World Health Organization (WHO) recommends the use of TST in low- and middle-income countries due to the high prevalence of latent $\mathrm{TB}$ and high cost of IGRA [49].

\section{TST}

The literature supports the following ranges in considering a result positive: for immunosuppressive subjects $>5 \mathrm{~mm}$, for immunocompetent subjects $>10$ $\mathrm{mm}$, and for healthcare workers $>15 \mathrm{~mm}$. In subjects who had any condition of immunosuppression and a negative TST, the test must be repeated 4 to 6 weeks after the first one (booster test); if the second test increases $5 \mathrm{~mm}$ or more, it is positive, and the patient should receive prophylaxis treatment [48].

If the subject required biological therapy or some immunosuppressive drug, treatment of latent tuberculosis infection (LTBI) with isoniazid (300 mg per day for 6-9 months) and pyridoxine $(50 \mathrm{mg}$ ) should be initiated. The patient should initiate the biological therapy one month after starting isoniazid [50]. Also, they should have chest radiograph, total abdominal ultrasound, and adequate physical examination in order to confirm or discharge active TB [46].

In populations with low TB prevalence, a negative TST result must be reassessed every year in order to identify a possible infection if the patient had recent history of travel or risk contact $[15,46]$. However, our recommendation, in countries with high TB prevalence, is that TST should be repeated, in order to confirm or rule out a new infection or reinfection. An increment of $5 \mathrm{~mm}$ compared with previous TST must be considered a reinfection in high burden TB countries, and patients should be screened again. 


\section{IGRA}

IGRA is a whole-blood test that can aid with $M$. tuberculosis infection diagnosis. Two IGRAs have been approved by the Food and Drug Administration and are commercially available. They are QuantiFERON: TB Gold In-Tube test (QFT-GIT) and SPOT TB test (TSPOT) [51,52]. IGRA measures a person's immune reactivity. White blood cells that have been infected with $M$. tuberculosis will release interferon gamma when mixed with antigens $[51,52]$.

IGRA has many advantages. Only one visit is required to conduct the test, results are ready in 24 hours, it is not necessary to reassess the test for a booster, and prior BCG vaccination does not interfere with the test result [51]. IGRA is good test for highincome countries; however, the WHO recommends the TST [49].

We recommend that screening always be done. The specialist should decide to use TST or IGRA based on cost, availability, patient history, and country. It is recommended to make the control test with the same test used previously.

\section{Lifestyle recommendations}

It is important for patients to know about the lifestyle factors that play a role; for example, in intestinal parasitic infections, proper cleaning of vegetables and fruits, boiled water or use of filters, health education, hand washing, and use of shoes are important factors [38]. In addition, people should avoid eating uncooked food, contact with baby cats and unvaccinated animals, and contact with hospitals and sick people [15]. It is important take into account that immunocompromised pet owners are at risk of contracting infections caused by zoonotic pathogens; the consequences of this are often much more severe than in immunocompetent people and may be lethal [53]. As a result, the relationships between veterinarians, physicians, and patients is important; in physicians' advice to their patients, they must comment about their immunosuppression because veterinarians should take additional precautions [54].

\section{What about vaccines?}

Administration of inactivated vaccines is safe in immunosuppressed patients, and is not associated with higher risk and vaccine adverse effects. However, it is recommended that the vaccine be administered before commencing DMARDs, corticosteroids, and biological therapy because the immunogenicity will be more effective [26]. Inactivated vaccine administration, such as influenza, pneumococcal, HBV, HAV, tetanus, meningococcal and HPV vaccines, is recommended (Table 1) [26,55]. Live attenuated vaccines such as herpes zoster could be taken just before commencement of DMARDs or corticosteroid therapy [46,56,57]. Additionally, as suggested earlier, the patient's HAV status should be considered.

Live vaccines are contraindicated in immunosuppressed patients because of the risk of replication of the attenuated microorganism and invasive infection. However, some live vaccines, such as varicella zoster (VZV) and measles-mumps-rubella (MMR) have low risk of replication and can be used with some specifications and before commencement of immunosuppression therapy [26,57] (Table 1).

Table 1. Vaccines and recommendations for patients at risk related to biological therapies [26,55].

\begin{tabular}{ll}
\hline Vaccine & Recommendation \\
\hline Influenza virus & 1 dose, every year \\
Hepatitis B virus & 3 doses, day 0, month 1 and month 6 \\
Pneumococcal PCV 13 & 1 dose every year previously received PPSV23 \\
Pneumococcal PPSV23 & 1 dose every 5 years, prior to PCV 13 \\
Hepatitis A virus & 2 doses, day 0, month 6, in countries with moderate and higher incidence and travelers to higher- \\
Tetanus & incidence countries \\
Meningococcal & Follow recommendation to general population \\
Human papilloma virus & 2 doses of tetravalent conjugate vaccine in patients with asplenia or deficiency in complement \\
Herpes zoster virus & pathway \\
Measles mumps rubella virus & 1 doses, day 0, month 2, month 6, especially in patients with SLE \\
Varicella virus & corticosteroids \\
Yellow fever virus & Before start of DMARDs \\
\hline
\end{tabular}

PPSV: pneumococcal polysaccharides vaccines; PCV: pneumococcal conjugate vaccines; DMARDs: drugs modifying against rheumatic diseases; SLE: systemic lupus erythematosus. 


\section{Conclusions}

Biological therapy, especially immunosuppressant agents, significantly increase the risk for infectious diseases. There is plenty of information about infectious disease assessment in developed countries, but in tropical countries, this information is scarce. Diagnostic accuracy for infectious diseases in tropical scenarios is challenging and requires a more complete assessment. Here we present a possible algorithm (Figure 1) to confirm or rule out possible active or latent infections. Additional assessment on this general topic should be performed to consider other emerging tropical infectious disease pathogens, such as chikungunya and Zika [58-60], and their potential life-threatening implications in these clinical settings [60]. Finally, we should acknowledge that this review has limitations regarding the available evidence for some recommendations. This directly implies the need for future research to validate or generate new recommendations.

\section{References}

1. Zink A, Thiele K, Huscher D, Listing J, Sieper J, Krause A, Gromnica-lhle E, von Hinueber U, Wassenberg S, Genth E, Schneider M (2006) Healthcare and burden of disease in psoriatic arthritis. A comparison with rheumatoid arthritis and ankylosing spondylitis. J Rheumatol 33: 86-90.

2. Burgos-Vargas R, Catoggio LJ, Galarza-Maldonado C, Ostojich K, Cardiel MH (2013) Current therapies in rheumatoid arthritis: A Latin American perspective. Reumatol Clin 9: 106-112.

3. Cárdenas-Roldán J, Rojas-Villarraga A, Anaya JM (2013) How do autoimmune diseases cluster in families? A systematic review and meta-analysis. BMC Med 11: 73.

4. Cantini F, Nannini C, Niccoli L, Iannone F, Delogu G, Garlaschi G, Sanduzzi A, Matucci A, Prignano F, Conversano M, Goletti D (2015) Guidance for the management of patients with latent tuberculosis infection requiring biologic therapy in rheumatology and dermatology clinical practice. Autoimmun Rev 14: 503-509.

5. Cantini F, Prignano F, Goletti D (2014) Restarting biologics and management of patients with flares of inflammatory rheumatic disorders or psoriasis during active tuberculosis treatment. J Rheumatol 91: 78-82.

6. Cardiel MH, Pons-Estel BA, Sacnun MP, Wojdyla D, Saurit V, Marcos JC, Pinto MR, Cordeiro de Azevedo AB, da Silveira IG, Radominski SC, Ximenes AC, Massardo L, Ballesteros F, Rojas-Villarraga A, Oñate RV, Hernandez MP, EsquivelValerio JA, García-De La Torre I, Khoury VJ, Millán A,

Figure 1. Infection diseases assessment algorithm for patient requiring biological therapy.

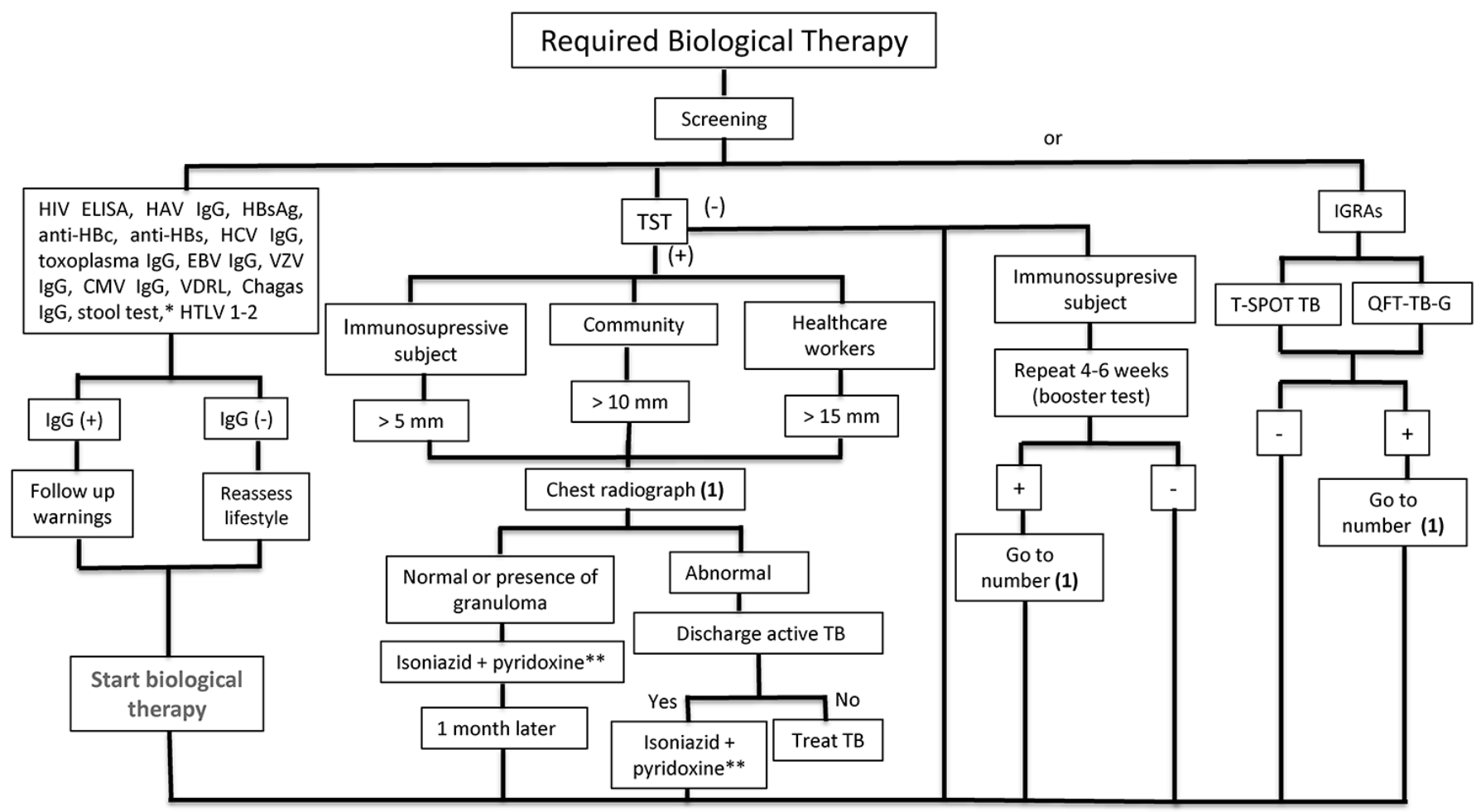

Anti-HBc: hepatitis B core antibody; anti-HBs: hepatitis B surface antibody; CMV: cytomegalovirus; EBV: Epstein-Barr virus; ELISA: enzyme-linked immunosorbent assay; HAV: hepatitis A virus; HBsAg: hepatitis B surface antigen; HCV: hepatitis C virus; HIV: human immunodeficiency virus; HTLV12: human T-lymphotropic virus; IgG: immunoglobulin G; IGRA: interferon gamma release assay; TST: tuberculin skin test; VDRL: venereal disease research laboratory; VZV: varicella zoster virus. ${ }^{*} \mathrm{HTLV}-1$ and 2 serology test are only recommended for countries with high prevalence of the infection.

**Isoniazid and pyridoxine doses according to international recommendation for latent TB. 
Soriano ER (2012) Treatment of early rheumatoid arthritis in a multinational inception cohort of Latin American patients: The GLADAR Experience. J Clin Rheumatol 18: 327-335.

7. Chevreul K, Haour G, Lucier S, Harvard S, Laroche ML, Mariette X, Saraux A, Durand-Zaleski I, Guillemin F, Fautrel B (2014) Evolution of direct costs in the first years of rheumatoid arthritis: impact of early versus late biologic initiation--an economic analysis based on the ESPOIR cohort. PLoS One 9: e97077.

8. Bodur H, Ataman S, Akbulut L, Evcik D, Kavuncu V, Kaya T, Günaydin R, Kuran B, Kotevoğlu N, Bal A, Aydoğ E, Altay Z, Uğurlu H, Kocabaş H, Olmez N, Yazgan P, Gürsoy S, Madenci E, Ozel S, Delialioğlu SU (2008) Characteristics and medical management of patients with rheumatoid arthritis and ankylosing spondylitis. Clin Rheumatol 27: 1119-1125.

9. Laires PA, Exposto F, Mesquita R, Martins AP, CunhaMiranda L, Fonseca JE (2013) Patients' access to biologics in rheumatoid arthritis: A comparison between Portugal and other European countries. Eur J Health Econ 14: 875-885.

10. Montoya N, Gómez L, Vélez M, Rosselli D (2011) Direct costs of treatment of patients with rheumatoid arthritis in Medellín, Colombia. Rev Colomb Reumatol 18: 26-33. [Article in Spanish.]

11. Benegas M, Muñoz-Gomariz E, Font P, Burgos-Vargas R, Chaves J, Palleiro D, Maldonado Cocco J, Gutiérrez M, Sáenz R, Steckmen I, Rillo O, Mulero J, Sampaio-Barros P, Barcelos A, Vander Cruyssen B, Vazquez-Mellado J, Collantes Estevez E (2012) Comparison of the clinical expression of patients with ankylosing spondylitis from Europe and Latin America. J Rheumatol 39: 2315-2320.

12. Wallis D, Thavaneswaran A, Haroon N, Ayearst R, Inman RD (2015) Tumour necrosis factor inhibitor therapy and infection risk in axial spondyloarthritis: results from a longitudinal observational cohort. Rheumatology (Oxford) 54: 152-156.

13. Germano V, Cattaruzza MS, Osborn J, Tarantino A, Di Rosa R, Salemi S, D'Amelio R (2014) Infection risk in rheumatoid arthritis and spondyloarthropathy patients under treatment with DMARDs, corticosteroids and TNF- $\alpha$ antagonists. J Transl Med 12: 77.

14. Andersen NN, Jess T (2014) Risk of infections associated with biological treatment in inflammatory bowel disease. World $\mathrm{J}$ Gastroenterol 20: 16014-1619.

15. Selmi C, Ceribelli A, Naguwa SM, Cantarini L, Shoenfeld Y (2015) Safety issues and concerns of new immunomodulators in rheumatology. Expert Opin Drug Saf 14: 389-399.

16. Winthrop KL (2012) Infections and biologic therapy in rheumatoid arthritis. Rheum Dis Clin North Am 38: 727-745.

17. Novosad SA, Winthrop KL (2014) Beyond tumor necrosis factor inhibition: the expanding pipeline of biologic therapies for inflammatory diseases and their associated infectious sequelae. Clin Infect Dis 58: 1587-1598.

18. Singh JA, Cameron C, Noorbaloochi S, Cullis T, Tucker M, Christensen R, Ghogomu ET, Coyle D, Clifford T, Tugwell P, Wells GA (2015) Risk of serious infection in biological treatment of patients with rheumatoid arthritis: a systematic review and meta-analysis. Lancet 386: 258-265.

19. Codreanu C, Damjanov N (2015) Safety of biologics in rheumatoid arthritis: data from randomized controlled trials and registries. Biologics 9: 1-6.

20. Rojas-Villarraga A, Agudelo CA, Pineda-Tamayo R, Porras A, Matute G, Anaya JM (2007) Tuberculosis in patients treated with tumor necrosis factor-alpha antagonists living in an endemic area. Is the risk worthwhile? Biomedica 27: 159-171.
21. Dewedar AM, Shalaby MA, Al-Homaid S, Mahfouz AM, Shams OA, Fathy A (2012) Lack of adverse effect of antitumor necrosis factor-alpha biologics in treatment of rheumatoid arthritis: 5 years follow-up. Int J Rheum Dis 15: 330-335.

22. Salliot C, Dougados M, Gossec L (2009) Risk of serious infections during rituximab, abatacept and anakinra treatments for rheumatoid arthritis: meta-analyses of randomised placebocontrolled trials. Ann Rheum Dis 68: 25-32.

23. Winthrop KL, Calabrese LH (2011) Let the fog be lifted: screening for hepatitis B virus before biological therapy. Ann Rheum Dis 70: 1701-1703.

24. Calabrese LH, Zein NN, Vassilopoulos D (2006) Hepatitis B virus (HBV) reactivation with immunosuppressive therapy in rheumatic diseases: assessment and preventive strategies. Ann Rheum Dis 65: 983-989.

25. Bühler S, Visser LG (2014) Hepatitis A vaccination in patients with rheumatic diseases and drug-induced immunosuppression. Travel Med Infect Dis 12: 115-117.

26. Papadopoulou D, Tsoulas C, Tragiannidis A, Sipsas NV (2015) Role of vaccinations and prophylaxis in rheumatic diseases. Best Pract Res Clin Rheumatol 29: 306-318.

27. Askling HH, Rombo L, Van Vollenhoven R, Hallén I, Thörner $\AA$, Nordin M, Herzog C, Kantele A (2014) Hepatitis A vaccine for immunosuppressed patients with rheumatoid arthritis: A prospective, open-label, multi-centre study. Travel Med Infect Dis 12: 134-142.

28. Ciocca M, Moreira-Silva SF, Alegría S, Galoppo MC, Ruttiman R, Porta G, Da Silvera TR, Rubio P, Macias M, Cervantes Y, Avila-Aguero ML, Clemens SA, Clemens R, Weil J (2007) Hepatitis A as an etiologic agent of acute liver failure in Latin America. Pediatr Infect Dis J 26: 711-715.

29. Pinazo M-J, Espinosa G, Gállego M, López-Chejade PL, Urbina JA, Gascón J (2010) Successful treatment with posaconazole of a patient with chronic Chagas disease and systemic lupus erythematosus. Am J Trop Med Hyg 82: 583587.

30. Pinazo MJ, Espinosa G, Cortes-Lletget C, Posada Ede J, Aldasoro E, Oliveira I, Muñoz J, Gállego M, Gascon J (2013) Immunosuppression and Chagas disease: a management challenge. PLoS Negl Trop Dis 7: e1965.

31. Sartori AM, Shikanai-Yasuda MA, Amato Neto V, Lopes MH (1998) Follow-up of 18 patients with human immunodeficiency virus infection and chronic Chagas' disease, with reactivation of Chagas' disease causing cardiac disease in three patients. Clin Infect Dis 26: 177-179.

32. Ferreira MS (1999) Chagas disease and immunosuppression. Mem Inst Oswaldo Cruz 94 Suppl 1: 325-327.

33. Ferreira MS, Borges AS (2002) Some aspects of protozoan infections in immunocompromised Patients- a review. Mem Inst Oswaldo Cruz 97: 443-457.

34. Cossermelli W, Friedman H, Pastor EH, Nobre MR, Manzione A, Camargo ME, Shiroma M (1978) Polymyositis in Chagas's disease. Ann Rheum Dis 37: 277-280.

35. dos Santos-Neto LL, Polcheira MF, Castro C, Correa Lima RA, Kozak Simaan C, Correa-Lima FA (2003) High parasitemia of Trypanosoma cruzi in a patient with systemic lupus erythematous. Rev Soc Bras Med Trop 36: 613-615. [Article in Portuguese.]

36. de Andrade-Nishioka S (2000) Benznidazol in the primary chemotherapy for Chagas disease reactivation in patients with chronic disease using stereoid in immunosuppresive doses: is 
there evidence for recommend its use? Rev Soc Bras Med Trop 33: 83-85. [Article in Portuguese.]

37. Pereira IR, Vilar-Pereira G, Silva AA, Moreira OC, Britto C, Sarmento ED, Lannes-Vieira J (2014) Tumor necrosis factor is a therapeutic target for Immunological unbalance and cardiac abnormalities in chronic experimental Chagas' heart disease. Mediators Inflamm 2014: 798078.

38. Braz AS, de Andrade CA, da Mota LM, Lima CM (2015) Recommendations from the Brazilian Society of Rheumatology on the diagnosis and treatment of intestinal parasitic infections in patients with autoimmune rheumatic disorders. Rev Bras Reum 55: 368-380.

39. Denis M, Chadee K (1988) Immunopathology of Entamoeba histolytica infections. Parasitol Today 4: 247-252.

40. Rodrigues MA, Fróes RC, Anefalos A, Kobayasi S (2001) Invasive enteritis by Strongyloides stercoralis presenting as acute abdominal distress under corticosteroid therapy. Rev Hosp Clin Fac Med Sao Paulo 56: 103-106.

41. Basile A, Simzar S, Bentow J, Antelo F, Shitabata P, Peng SK, Craft N (2010) Disseminated Strongyloides stercoralis: hyperinfection during medical immunosuppression. J Am Acad Dermatol 63: 896-902.

42. Magalhães MB, Donadi EA, Louzada Jr P (2003) Clinical Manifestitations of of Systemic Lupus Erythematouos: diagnostic and therapeutic approach at the emergency room. Medicina, Ribeirão Preto 36: 409-417. [Article in Portuguese.]

43. Santiago M, Leitão B (2009) Prevention of strongyloides hyperinfection syndrome: a rheumatological point of view. Eur J Intern Med 20: 744-748.

44. Verdonck K, González E, Van Dooren S, Vandamme AM, Vanham G, Gotuzzo E (2007) Human T-lymphotropic virus 1: recent knowledge about an ancient infection. Lancet Infect Dis 7: 266-281.

45. Marinho J, Galvão-Castro $B$, Rodrigues LC, Barreto $\mathrm{ML}$ (2005) Increased risk of tuberculosis with human Tlymphotropic virus-1 Infection: a case control study. J Acquir Immune Defic Syndr 40: 625-628.

46. Singh JA, Furst DE, Bharat A, Curtis JR, Kavanaugh AF, Kremer JM, Moreland LW, O'Dell J, Winthrop KL, Beukelman T, Bridges SL Jr, Chatham WW, Paulus HE, Suarez-Almazor M, Bombardier C, Dougados M, Khanna D, King CM, Leong AL, Matteson EL, Schousboe JT, Moynihan E, Kolba KS, Jain A, Volkmann ER, Agrawal H, Bae S, Mudano AS, Patkar NM, Saag KG (2012) 2012 update of the 2008 American College of Rheumatology recommendations for the use of disease-modifying antirheumatic drugs and biologic agents in the treatment of rheumatoid arthritis. Arthritis Care Res 64: 625-639.

47. Grupo Funcional Nacional de Tuberculosis (2009) Strategic Plan for Colombia free of TB 2010-2015 for the expansion and strenghtening of Stop TB programs. third edition. Ministerio Proteccion Social Republica de Colombia [Article in Spanish.]

48. Lee SW, Oh SY, Lee JB, Choi CM, Kim HJ (2014) Tuberculin skin test distribution following a change in BCG Vaccination policy. PLoS One 9: e86419.

49. World Health Organization (2011) Use of tuberculosis interferon-gamma release assay (IGRAs) in low- and middleincome countries. Policy Statement. Geneva: WHO. 70 p.
50. Pérez CE, Borda A (2007) Interpretation of PPG, fundaments and physiolopathology. Practical approach. Rev Colomb Neumol 19: 11-17. [Article in Spanish.]

51. National Center for HIV/AIDS, Viral Hepatitis, STD, and TB Prevention, Division of Tuberculosis Elimination (2011) TB Elimination, interferon gamma release assays (IGRAs) - blood test for TB infection. Atlanta: Centers for Disease Control and Prevention. 3 p.

52. Dorman SE, Belknap R, Graviss EA, Reves R, Schluger N, Weinfurter P, Wang Y, Cronin W, Hirsch-Moverman Y, Teeter LD, Parker M, Garrett DO, Daley CL (2014) Interferon- $\gamma$ release assays and tuberculin skin testing for diagnosis of latent tuberculosis infection in healthcare workers in the united states. Am J Respir Crit Care Med 189: 77-87.

53. Elad D (2013) Immunocompromised patients and their pets: still best friends? Vet J 197: 662-669.

54. Grant S, Olsen CW (1999) Preventing zoonotic diseases in immunocompromised persons: the role of physicians and veterinarians. Emerg Infect Dis 5: 159-163.

55. Brenol CV, da Mota LM, Cruz BA, Pileggi GS, Pereira IA, Rezende LS, Bertolo MB, Freitas MV, Silva NA, LouzadaJunior P, Giorgi RD, Lima RA, Pinheiro Gda R (2013) 2012 Brazilian Society of Rheumatology Consensus on vaccination of patients with rheumatoid arthritis. Rev Bras Reumatol 53: 423.

56. Grupo De Expertos, Comité de Vacunacion del Adulto Asociación Colombiana de Infectología (2012) Clinical practice guideline for the immunization of the adolescent and adults in Colombia 2012. Infectio 16 Suppl 2: 5-48. [Article in Spanish.]

57. Guarnizo-Zuccardi P, Eraso-Garnica RM, Ramírez-Gómez LA (2006) Immunization of patients with rheumatic diseases. Rev Colomb Reumtol 13: 65-75. [Article in Spanish.]

58. Alfaro-Toloza P, Clouet-Huerta DE, Rodríguez-Morales AJ (2015) Chikungunya, the emerging migratory rheumatism. Lancet Infect Dis 15: 510-512.

59. Rodríguez-Morales AJ (2015) Zika: the new arbovirus threat for Latin America. J Infect Dev Ctries 9: 684-685. doi:10.3855/jidc. 7230 .

60. Arzusa-Ortega L, Polo A, Pérez-Tatis G, López-García H, Parra E, Pardo-Herrera LC, Rico-Turca AM, Villamil-Gómez W, Rodríguez-Morales AJ (2016) Fatal Sickle Cell Disease and Zika Virus Infection in Girl from Colombia. Emerg Infect Dis 22: 925-927.

\section{Corresponding author}

Alfonso J. Rodriguez-Morales, MD, MSc, FFTM RCPSG, FACE Public Health and Infection Research Group,

Faculty of Health Sciences, Universidad Tecnológica de Pereira

Pereira 660001

Risaralda, Colombia

Phone: +573008847448

Fax: +573008847448

Email: arodriguezm@utp.edu.co

Conflict of interests: No conflict of interests is declared. 